\title{
Current Account, Capital Formation and Terms of Trade Shocks: a Revisit of the Harberger-Laursen-Metzler Effect
}

\author{
Hung-Ju Chen and Chen-Min Hsu
}

Received January 27, 2005; revised version received December 21, 2005

Published online: May 30, 2006

(C) Springer-Verlag 2006

This paper extends the Blanchard model of a closed-economy to a three-good (exportable, importable and non-tradable goods) open-economy model with capital accumulation and uncertain lifetimes to study the impacts of terms of trade shocks on the current account. The simulation results show that a model with uncertain lifetimes is more appropriate to describe a small open economy like Taiwan at the steady-state equilibrium than a model with infinite lifetimes. We find that the Harberger-Laursen-Metzler effect is discernible for temporary or permanent terms of trade shocks. Furthermore, the steady state is a saddle point and the speed of convergence of capital and consumption is quite low.

Keywords: terms of trade, current account, Harberger-Laursen-Metzler effect.

JEL Classification: F11, F32, F47.

\section{Introduction}

Small open economies tend to be easily disturbed by external shocks through international trade. The change of terms of trade can have great influences on the economic performance (such as output, savings and current account) of export-orientated countries like Japan, South Korea and Taiwan. The fluctuations of output caused by the terms of trade shocks differ from the traditional real business cycle model since the shocks come from demand shocks instead of supply shocks. 
Numerous works have been dedicated to study the impacts of deteriorations in terms of trade faced by small open economies. The early studies by Harberger (1950) and Laursen and Metzler (1950) showed that a decrease in current income arising from an adverse terms of trade shock would lower both private savings and the current account balance. Using an intertemporal optimization framework with infinitely-lived households, Obstfeld (1982a) revisited the issue of terms of trade shocks and found that the HarbergerLaursen-Metzler effect failed to hold when there was a permanent deterioration in terms of trade. However, Obstfeld $(1982 b ; 1983)$ showed that a temporary worsening of terms of trade led to a current account deficit, but that when terms of trade reverted to their original level, the current account would move into surplus and ultimately back to its initial steady-state level. ${ }^{1}$

Svesson and Razin (1983) adopted a two-period, two-good (importable and exportable goods) framework to reexamine Obstfeld's propositions and found that there were deteriorations in the current account and savings as a result of temporary deterioration in terms of trade, but that this might go either way as a result of any permanent deterioration. The study by Sen and Turnovsky (1989) indicated that the HarbergerLaursen-Metzler effect depended on whether or not the income effect dominated the substitution effect during the deterioration of terms of trade. A representative-individual intertemporal model was adopted by Mendoza (1995) and Kose (2002) to investigate the impact of terms of trade shocks on the current account. Mendoza (1995) found that there was a temporary Harberger-Laursen-Metzler effect, but there was no permanent Harberger-Laursen-Metzler effect in industrialized countries while Kose (2002) found that about 95 per cent of fluctuations in the trade balance were positively accounted for by terms of trade shocks in developing countries.

Traditional studies tend to use a two-good open model to study the Harberger-Laursen-Metzler effect and neglect the role of non-tradable goods. However, when terms of trade shocks happen, consumption (saving) and investment behaviors play important roles in determining the changes of the current account. A change in terms of trade will affect the real income and consumption spending. It will not only change the amount of consumption spending, but also the composition of spending (the amount spent on importable goods, exportable goods and

1 In Obstfeld (1982a), there was a varying rate of time preference while in Obsfeld (1982b; 1983), there was a constant rate of time preference. 
non-tradable goods). The change in terms of trade implies that the relative price of the imported capital goods will change and this will affect the amount of investment for firms. Furthermore, firms also need to adjust the capital allocation for the exportable-goods and importable-goods sector based on the changes of the price of exportable goods relative to importable goods.

The contribution of this paper is to revisit the Harberger-LaursenMetzler effect of terms of trade shocks in a three-good (exportable, importable and non-tradable goods) open model with capital formation and uncertain lifetimes. Based on the study by Chen et al. (2005) of a two-good open economy, ${ }^{2}$ we continue with the analysis of a three-good (exportable, importable and non-tradable goods) model with capital accumulation in this paper. We extend Engel and Kletzer (1990) and the Blanchard-style (1985) overlapping generations model with finite lifetimes to a three-good open economy in which the production structure is similar to that of Mendoza (1995).

In this paper, capital formation and non-tradable goods are incorporated into the framework, where we assume that capital is only used to produce tradable goods (exportable and importable goods) and installation costs are involved to study firms' investment behavior. ${ }^{3}$ This assumption allows us to simplify the analytical framework since it disposes of the requirement to consider the capital reallocation effect between tradable and non-tradable sectors. ${ }^{4}$ Instead of adopting a

2 The results of Chen et al. (2005) show that without incorporating capital formation, a permanent deterioration in terms of trade will lead to an increase in savings and an improvement in the current account if the rate of time preference is greater than the real interest rate and if the intertemporal elasticity of substitution is sufficiently high.

3 In this paper, we assume that capital is imported from foreign countries. Implications of international capital flows on the current account in a two-country world were studied by Walde (1996). Models with costly investment can be found in Brock (1988), Sen and Turnovsky (1989a; 1989b), and Mahbub Morshed and Turnovsky (2004), and the nature of investment is important for the dynamics. In the absence of any installation costs, capital stock adjustment occurs instantaneously.

4 A detailed analysis of the real exchange rate dynamics and their interaction with capital accumulation in a two-sector dependent economy can be found in Brock (1996) and Mahbub Morshed and Turnovsky (2004), with the latter showing that by incorporating the inter-sectoral adjustment costs of capital movement, both the dynamics of capital accumulation and real exchange rate were sensitive to the degree of adjustment costs. 
representative agent model as the real business cycle model usually does, we then use an overlapping generations model where agents have finite lifetimes to study household's savings behavior.

Our study shows that the economic performance of a small open economy can be represented by a four by four dynamical system (four first-order difference equations of consumption, capital, foreign assets and shadow price of capital). Because of the complication of the dynamic system, we then simulate the model to study the investment and saving behavior and the existence of Harberger-Laursen-Metzler effect. We choose to calibrate the parameter values using 1990 data of Taiwan because Taiwan is a small open economy relying heavily on the international trade. Our computational results show that a steady-state solution does exist, and that it is a saddle point. However, the steady state is very sensitive to the arrival rate of death. We find that a model with uncertain lifetimes is more appropriate to describe a small open economy like Taiwan at the steady-state equilibrium than a model with infinite lifetimes.

We also find that a temporary or permanent deterioration in terms of trade implies a worsening of the trade balance; that is, we observe the presence of the Harberger-Laursen-Metzler effect. The numerical results show that a temporal increase of the terms of trade will cause consumption to increase sharply and both capital and the current account will increase temporarily. When the terms of trade increase by 5 per cent permanently, capital will increase by $2.8 \%$, consumption will increase by $3.2 \%$ and the current account will decrease temporarily and then increase by $3.6 \%$ at the steady state. The reason that the current account reacts differently to temporary and permanent terms of trade shocks is that permanent shocks induce larger changes in the permanent income and this in turn causes larger changes in consumption. Our results further show that, as demonstrated by Barro and Sala-i-Martin (2004), the speed of convergence of capital and consumption is quite low.

The remainder of this paper is organized as follows. An open economy with capital accumulation to study firms' investment behavior and with uncertain lifetimes to study household's savings behavior is developed in the next section. The parameter values are calibrated and the model is simulated in Sect. 3 to study the impacts of the terms of trade shocks. The final section presents the conclusions drawn from this study. 


\section{The Production Model}

\subsection{Firms}

In this section, we endogenize production and capital accumulation into an open economy. In contrast to the two-good open economy model, as in Sen and Turnovsky (1989a; 1989b), and Engel and Kletzer (1990), we also incorporate non-tradable goods and examine the additional effects of terms of trade shocks stemming from changes in the real exchange rate. Hence, goods are categorized into exportable, importable and nontradable goods.

It is assumed that capital goods are imported from foreign countries, and indeed, this is the case for most developing countries ${ }^{5}$ Following Mendoza (1995), importable goods are taken as the numeraire. The relative price of exportable goods, i.e., terms of trade, is denoted by $P_{X}{ }^{6}$ The relative price of non-tradable goods is $P_{N}$, which is defined as the real exchange rate. Exportable goods $(X)$ and importable goods $(M)$ are produced using both capital and labor, whilst non-tradable goods $(N)$ are produced using only labor. The supply of labor in the tradable sector is assumed to be inelastic, whilst in the non-tradable sector it is assumed to be elastic. ${ }^{7}$ Capital is homogeneous and freely mobile across sectors without any cost. However, capital is assumed to be installed with adjustment costs. Because capital can freely move between importable and exportable sectors, the decentralized solutions for the representative firms in importable and exportable sectors will be the same as those chosen by for a "planner" in the "tradable sector". The optimal behavior of a representative firm in the tradable sector can be described as follows:

5 Although domestic firms also produce importable goods, we assume that there are only sufficient domestically-produce importable goods for consumptions, and that all capital goods used for production are important.

6 The three sector (exportable, importable and non-tradable goods) model was also used by Ostry (1988). However, capital formation was not incorporated in his model. Ostry and Reinhart (1992) and Cashin and McDermott (2003) adopted a simple three sector model to empirically test the effects of terms of trade shocks on economic performance for developing and industrial countries, respectively.

7 In addition to the setting that labor was "inelastically" supplied to the traded sector, Mendoza (1995) similarly assumed that capital was "inelastically" supplied to the non-traded sector. 


$$
\begin{gathered}
V_{t}=\max _{K_{X}, I} \int_{t}^{\infty}\left\{P_{X} X\left(K_{X}, L_{X}\right)+M\left(K_{M}, L_{M}\right)-W_{X} L_{X}-W_{M} L_{M}\right. \\
-I[1+J(I / K)]\} e^{-r(v-t)} d v, \\
\text { s.t. } \quad K_{X}+K_{M}=K, \\
\dot{K}=I,
\end{gathered}
$$

where time notation is omitted without confusion. Variables $K_{i}$ and $\operatorname{Li}(i=X, M)$ respectively represent capital and labor employed to produce good $i$. Depreciation of capital goods is ignored here. The global real interest rate is denoted as $r$, which is constant for a small open economy. Production functions of $X$ and $M$ are presented by $X($.$) and M($.$) . The$ respective wage rates of $L_{X}$ and $L_{M}$ are $W_{X}$ and $W_{M}$. Investment is represented by $I$, and $J(I / K)$ is an installment cost function with $J(0)=0, J^{\prime}>0$ and $J^{\prime \prime}=0$.

The planner in the tradable sector will optimize Eq. (1) subject to Eqs. (2) and (3) by choosing how to allocate capital in the tradable sector $\left(K_{X}\right)$ and investment $(I)$. The optimality conditions are:

$$
\begin{gathered}
P_{X} X_{K}=M_{K}, \\
\eta=1+J^{\prime}(I / K) \cdot[I / K], \\
\dot{\eta}=r \eta-\left[M_{K}+J^{\prime}(I / K) \cdot[I / K]^{2}\right],
\end{gathered}
$$

where $X_{K}$ and $M_{K}$ are the marginal product of capital of exportable and importable goods, $\eta$ is the shadow price of capital goods, and the production function is assumed to be linearly homogeneous in capital and labor. Solving Eqs. (2) and (4), we have:

$$
\begin{aligned}
& K_{X}=K_{X}\left(K, P_{X}\right), \\
& K_{M}=K_{M}\left(K, P_{X}\right),
\end{aligned}
$$

with $\quad K_{X}^{\prime}=\frac{M_{K K}}{M_{K K}+P_{X} X_{K K}}>0, \quad K_{M}^{\prime}=\frac{P_{X} X_{K K}}{M_{K K}+P_{X} X_{K K}}>0$, 
where $K_{X}^{\prime}$ and $K_{M}^{\prime}$ are the first-order derivatives of $K_{X}($.$) and K_{M}($.$) with$ respect to $K$; and $M_{K K}$ and $X_{K K}$ denote the second-order derivatives of $M$ and $X$ with respect to $K_{M}$ and $K_{X}$. By Eq. (5), the optimal investment function is

$$
I=\frac{[\eta-1] K}{J^{\prime}(I / K)}
$$

Because the installment cost function $J(I / K)$ is linear in $J / K$, the optimal investment function depends on $(\eta-1)$ and $K$ :

$$
I=\phi(\eta-1) \cdot K
$$

where $\phi(\eta-1)=\eta-1$. Notice that $\phi(0)=0$ and $\phi^{\prime}(0)>0$.

Dynamic equations can be obtained from Eqs. (3), (6) and (9):

$$
\begin{gathered}
\dot{K}=\phi(\eta-1) K \\
\dot{\eta}=r \eta-\left[M_{K}+J^{\prime}(\phi(\eta-1)) \cdot(\phi(\eta-1))^{2}\right] .
\end{gathered}
$$

We assume that labor is the only input in the non-tradable sector. The optimal behavior of the representative non-tradable goods firm can thus be described as

$$
\max \int_{t}^{\infty}\left[P_{N} G\left(L_{N}\right)-W_{N} L_{N}\right] e^{-r(v-t)} d v
$$

where $G($.$) is the production function of non-tradable goods (which is$ assumed to have constant returns to scale), $L_{N}$ is the labor allocation for the production of the non-tradable goods, and $W_{N}$ is the wage rate of $L_{N}$. The optimality condition is therefore

$$
P_{N} G_{L}=W_{N}
$$

where $G_{L}$ is the marginal productivity of $L_{N}$. 


\subsection{Households}

We assume that the economy consists of identical households with a constant life expectancy, and that there is no population growth. ${ }^{8}$ At each instant, a new cohort of size $\beta$ is born so that the size of the total population at any given time is normalized as one.

Assuming that there exist perfect annuity markets, in the absence of bequest motive and with negative bequest prohibited, individuals will contract to pay non-human wealth $a$ to insurance companies contingent on their death to receive $\beta a$ per unit of time. Thus the effective rate of return on non-human wealth is $r+\beta$. As a result of uncertain lifetime expectancy, each household's effective subjective discount rate is $\rho+\beta$, where $\rho$ is the positive pure rate of time preference.

We assume that households consume exportable goods $\left(c_{X}\right)$, importable goods $\left(c_{M}\right)$, non-tradable goods $\left(c_{N}\right)$ and leisure $(L)$. For agents born at time $s$, we define total household expenditure as $c(s, t)=P_{X} c_{X}(s, t)+$ $c_{M}(s, t)+P_{N} c_{N}(s, t)$. Starting from the current time $t$, the household at time $s$ maximizes expected utility, given by

$$
\max E_{t}\left[\int_{t}^{\infty} U\left(c_{X}(s, v), c_{M}(s, v), c_{N}(s, v), L(s, v)\right) e^{-\rho(v-t)} d v\right] .
$$

Conditioned on being alive at the earlier time $t$, the probability of being alive at time $v$ is $e^{-\beta(v-t)}$. Hence, the expected lifetime utility becomes:

$$
\int_{t}^{\infty} U\left(c_{X}(s, v), c_{M}(s, v), c_{N}(s, v), L(s, v)\right) e^{-(\rho+\beta)(v-t)} d v .
$$

The budget constraint for the household is

$$
\int_{t}^{\infty} c(s, v) e^{-(r+\beta)(v-t)} d v \leq a(s, t)+h(s, t),
$$

8 Let $\beta$ be the constant probability of instantaneous death and assume that the random variable "time until death" has an exponential distribution; then expected lifetime is equal to the expected value of the random variable which is $1 / \beta$; in other words, $1 / \beta$ can be thought of as an index of the effective horizon of individuals. As $\beta$ goes to zero, the horizon becomes infinite, and we have the Ramsey-Cass-Koopmans model. 


$$
\begin{gathered}
\text { where } c(s, t)=P_{X} c_{X}(s, t)+c_{M}(s, t)+P_{N} c_{N}(s, t), \\
h(s, t)=\int_{t}^{\infty}(y(v)-\tau(v)) e^{-(r+\beta)(v-t)} d v \\
=\int_{t}^{\infty}\left[W_{X}(v) L_{X}+W_{M}(v) L_{M}+W_{N}(v) L_{N}(s, v)-\tau(v)\right] e^{-(r+\beta)(v-t)} d v
\end{gathered}
$$

where $a(t)$ and $h(t)$ represent non-human wealth and human wealth respectively and $L(s, v)$ is leisure and $L_{N}(s, v)$ is the labor allocation for the production of the non-tradable goods, with $L_{X}+L_{M}+L_{N}+L=1$. The labor income and the lump-sum tax are denoted by $y(t)$ and $\tau(t)$, respectively. The consolidated lifetime budget constraint of Eq. (15) implies that

$$
\begin{aligned}
\dot{a}(s, t)= & (r+\beta) a(s, t)+W_{X}(t) L_{X}+W_{M}(t) L_{M}+W_{N}(t) L_{N}(s, t) \\
& -\tau(t)-c(s, t) .
\end{aligned}
$$

Hence, Eq. (17) can be rewritten as

$$
\begin{aligned}
h(s, t)= & \int_{t}^{\infty}\left[W_{X}(v) L_{X}+W_{M}(v) L_{M}+W_{N}(v)\left(1-L_{X}-L_{M}\right)-\tau(v)\right] \\
& e^{-(r+\beta)(v-t)} d v-\int_{t}^{\infty} W_{N}(v) L(s, v) e^{-(r+\beta)(v-t)} d v, \\
\equiv & \int_{t}^{\infty} y^{f}(v) e^{-(r+\beta)(v-t)} d v-\int_{t}^{\infty} W_{N}(v) L(s, v) e^{-(r+\beta)(v-t)} d v, \\
\equiv & h^{f}(s, t)-\int_{t}^{\infty} W_{N}(v) L(s, v) e^{-(r+\beta)(v-t)} d v,
\end{aligned}
$$

where $y^{f}(v) \equiv W_{X}(v) L_{X}+W_{M}(v) L_{M}+W_{N}(v)\left(1-L_{X}-L_{M}\right)-\tau(v)$ is the full post-tax income of an individual, and $h^{f}(s, t) \equiv \int_{t}^{\infty} y^{f}(v)$ 
$e^{-(r+\beta)(v-t)} d v$ is the "full" post-tax human wealth. From Eqs. (15) and (17'), we obtain:

$$
\int_{t}^{\infty}\left[c(s, v)+W_{N}(v) L(s, v)\right] e^{-(r+\beta)(v-t)} d v \leq a(s, t)+h^{f}(s, t) .
$$

Let the instantaneous utility function $U\left(c_{X}, c_{M}, c_{N}, L\right)$ be in log form and additively separable for consumption and leisure. That is

$$
U\left(c_{X}, c_{M}, c_{N}, L\right)=\theta \sum_{i} \mu_{i} \log c_{i}+(1-\theta) \log L, \quad i=X, M, N,
$$

where $\theta$ is the contribution of consumption to utility, $\mu_{i}$ is the contribution of good $i$ to consumption, and $\sum_{i} \mu_{i}=1$. Solving the household's optimization problem and aggregating $C_{t}$ and $L_{t}$, we obtain that the dynamics of "full" human and non-human wealth become:"

$$
\begin{gathered}
\dot{A}(t)=r A(t)+Y^{f}(t)-C(t)-W_{N}(t) L(t), \\
\dot{H}^{f}(t)=(r+\beta) H^{f}(t)-Y^{f}(t),
\end{gathered}
$$

where

$$
\begin{gathered}
A(t)=\beta \int_{-\infty}^{t} a(s, t) e^{\beta(s-t)} d s, \\
H^{f}(t)=\beta \int_{-\infty}^{t} h^{f}(s, t) e^{\beta(s-t)} d s, \\
Y^{f}(t) \equiv \beta \int_{-\infty}^{t} y^{f}(s) e^{\beta(s-t)} d s .
\end{gathered}
$$

9 Detailed solutions of the household's optimization problem are given in Appendix 1. 
The dynamics of consumption can be written as

$$
\dot{C}(t)=(r-\rho) C(t)-\theta \beta(\rho+\beta) A(t) .
$$

Linear homogeneity of production and the convexity of adjustment cost function ensure that the value of the firm is equal to $\eta K .{ }^{10}$ Thus, nonhuman wealth comprises of foreign assets $(F)$ and equity, i.e.,

$$
A=F+\eta K
$$

\subsection{The Government}

In this section, we assume that the government also consumes nontradable goods and finances its consumption by means of taxation. Hence, the government budget constraint can be written as

$$
G(t)=P_{X}(t) G_{X}(t)+G_{M}(t)+P_{N}(t) G_{N}(t)=T(t)
$$

where $G_{N}(t)$ is government expenditure on non-tradable goods. From Eqs. (10), (11), (24), (25) and the market clearing condition for nontradable goods, $P_{N} N\left(L_{N}\right)=\left(1-\mu_{X}-\mu_{M}\right) C(t)+G_{N}(t)$, we obtain

$$
\begin{aligned}
\dot{F}= & r F+P_{X} X+M-\left(\mu_{X}+\mu_{M}\right) C \\
& +\left[J^{\prime}(\phi(\eta-1)) \cdot(\phi(\eta-1))^{2}-\eta \cdot \phi(\eta-1)\right] K-\left(G_{M}+P_{X} G_{X}\right) .
\end{aligned}
$$

Equations (10), (11), (23) and (26) describe the entire dynamic system. Thus, there are four equations in our system to determine the transitions of four variables $(K, \eta, C$ and $F)$. We use the asterisked variables to denote the steady-state values. Note that $\eta^{*}$ can be derived from Eq. (10). By setting $\dot{K}=0$, we can get that $\eta^{*}=1$. Because $\phi(0)=0$, the linearization of Eq. (10) around the steady state becomes

$$
\dot{K}=\phi\left(\eta^{*}-1\right)\left[K-K^{*}\right]+\phi^{\prime}\left(\eta^{*}-1\right) K^{*}\left[\eta-\eta^{*}\right]=\phi^{\prime}(0) K^{*}\left[\eta-\eta^{*}\right] .
$$

10 See Hayashi (1982) for the derivation. 
Linearizing the system around the steady state, we obtain:

$$
\begin{aligned}
{\left[\begin{array}{c}
\dot{K} \\
\dot{\eta} \\
\dot{C} \\
\dot{F}
\end{array}\right]=} & {\left[\begin{array}{cccc}
0 & \phi^{\prime}(0) K^{*} & 0 & 0 \\
-M_{K K} K_{M}^{\prime}\left(K^{*}\right) & r & 0 & 0 \\
-\theta \beta(\rho+\beta) & \theta \beta(\rho+\beta) K^{*} & r-\rho & -\theta \beta(\rho+\beta) \\
r & -\phi^{\prime}(0) K^{*} & -\left(\mu_{X}+\mu_{M}\right) & r
\end{array}\right] } \\
& {\left[\begin{array}{c}
K-K^{*} \\
\eta-1 \\
C-C^{*} \\
F-F^{*}
\end{array}\right] . }
\end{aligned}
$$

Since the characteristic matrix in system (27) is block recursive, there is little difficulty in obtaining the eigenvalues. Detailed analysis of the dynamic system is provided in Appendix 2. Four eigenvalues are roots of the following characteristic equations:

$$
\begin{gathered}
f_{1}(\lambda)=\lambda^{2}-r \lambda+\phi^{\prime}(0) M_{K K} K_{M}^{\prime}\left(K^{*}\right) K^{*}=0 \\
f_{2}(\lambda)=\lambda^{2}-(2 r-\rho) \lambda+\left[r(r-\rho)-\theta \beta(\rho+\beta)\left(\mu_{X}+\mu_{M}\right)\right]=0 .
\end{gathered}
$$

Equation (28) implies that one root is negative and another root is positive since the multiplication of these two roots equals $\phi^{\prime}(0) M_{K K} K_{M}^{\prime}\left(K^{*}\right) K^{*}<0$. We use $\lambda_{1}$ to represent the negative root of Eq. (28). Equation (29) implies that that there is one negative root and one positive root if $r(r-\rho)-\theta \beta(\rho+\beta)\left(\mu_{X}+\mu_{M}\right)<0$. Based on our calibration in the next section, the value of $r(r-\rho)-\theta \beta(\rho+\beta)\left(\mu_{X}+\mu_{M}\right)$ is negative and we use $\lambda_{2}$ to represent the negative root of Eq. (29).

\section{Simulations}

This subsection provides details of the calibration of the parameter values used for our simulations. We begin by considering an economy where the non-tradable sector uses only labor for production, choosing Taiwan to represent the small open economy in our model, and calibrating the remainder of the parameter values to the data for the year $1990 .^{11}$ The

11 Data source: Taiwan Statistical Data Book (2000). 
birth rate in Taiwan in 1990 was 1.66 per cent; thus, in our model setting, which enables each individual to give birth to one child, $\beta$ is set at 3.32 per cent. The real interest rate and the rate of time preference are set at 0.04 and 0.03 , respectively.

We assume that tradable sectors adopt Cobb-Douglas production functions to produce their exportable and importable goods. That is, $X\left(K_{X}, L_{X}\right)=K_{X}^{\xi_{1}} L_{X}^{1-\xi_{1}}$ and $M\left(K_{M}, L_{M}\right)=K_{M}^{\xi_{2}} L_{M}^{1-\xi_{2}}$. In 1990, 28.9 per cent of all exported goods from Taiwan were classified as high capitalintensity goods, whilst the proportion of all imports regarded as high capital-intensity goods was 46.4 per cent. Hence, we set $\xi_{1}=0.3$ and $\xi_{2}=0.35$ so that the importable goods sector is more capital intensive than the exportable goods sector.

The adjustment cost function of investment is set at $J(I / K)=b / 2 I / K$, and since the parameter value of $b$ only affects the speed of convergence and has no impact on the steady state $\left(K^{*}, \eta^{*}, C^{*}\right.$, $F^{*}$ ), we assign $b=10$. For simplicity, we assume that there is no government spending. ${ }^{12}$

Following Hansen and Imrohoroglu (1992), we assume that, after subtracting time spent on eating, sleeping and other personal care, agents will have a total of 98 hours per week available to invest in other activities. By assuming that individuals spend 45 hours per week working $^{13}$ and that the labor inputs of the exportable, importable and nontradable goods sectors are equal, we can then calculate that $L_{X}$ and $L_{M}$ are approximately 0.15 . The parameter value of $\theta$ is calibrated to 0.4766 , so that at the steady state, private consumption is 10 per cent of non-human wealth. Assuming that non-human wealth comprises of the same weight of foreign assets and equity at steady state, then $\mu_{X}+\mu_{M}$ is calibrated as 0.8085 .

According to the parameter values calibrated above, the steady-state equilibrium is characterized by $K^{*}=6.9, \quad \eta^{*}=1, \quad C^{*}=1.4$ and $F^{*}=6.9$. Using Eqs. (28) and (29) to solve for the four eigenvalues $-0.035,0.075,-0.007,0.057$, implies that the steady-state equilibrium is,

12 The inclusion of government spending on exportable and importable goods does not change our simulation results.

13 According to the Monthly Bulletin of Earnings and Productivity Statistics (2000), the average monthly working hours for employees in non-agricultural industries in Taiwan ranges from 189 to 204. 
as expected, a saddle point, since there are two jumping variables ( $\eta$ and $C)$ and two stock variables $(K$ and $F)$.

\subsection{Numerical Results}

Figures 1 and 2 present the simulation results on the effects of terms of trade shocks on the economy, respectively illustrating an unanticipated temporary appreciation in terms of trade and a permanent appreciation in terms of trade (that is, an increase in the relative price of exportable goods), with changes in consumption, capital, foreign assets and shadow price reacting differently in either case. ${ }^{14}$

Figure 1 illustrates the case of a temporary increase of 5 per cent, in the relative price of exportable goods, demonstrating that consumption, capital and foreign assets increase immediately after the appreciation of the terms of trade, and then move back to their original steady-state equilibrium. The speed of convergence is quite low because the absolute values of the negative eigenvalues are small.

Figure 2 describes the dynamic effects of a permanent ( 5 per cent) increase in the relative price of exportable goods. The new steady state is: $K^{*}=7.1, \eta^{*}=1, C^{*}=1.4$ and $F^{*}=7.1$, which demonstrates that, following appreciation in terms of trade, there is a sudden rise in consumption which then continues to gradually rise until it reaches the new steady state.

As shown in Fig. 2, capital also increases over time and will eventually converge to the value of the new steadystate; however, there is a discernible fall in foreign assets immediately after the shock. However thereafter, these assets gradually rise to the higher value of the new steady state. This differs from the case of a temporary increase, where there is no negative change in the value of foreign assets. When there is an appreciation in terms of trade, both real income and consumption will increase. Note that the change of consumption depends on the "revised" permanent income. If the shock is temporary, there will be a small increase in the permanent income and foreign assets will increase right after the shock. However, if the shock is permanent, there will be a larger increase in the permanent income which will in turn induce a larger increase in

14 We adopt the GEMPACK economic modelling software (Harrison and Pearson (1996)) to carry out our simulations; see Dixon et al. (1992), and Codsi et al. (1992) for an explanation of the algorithm. 

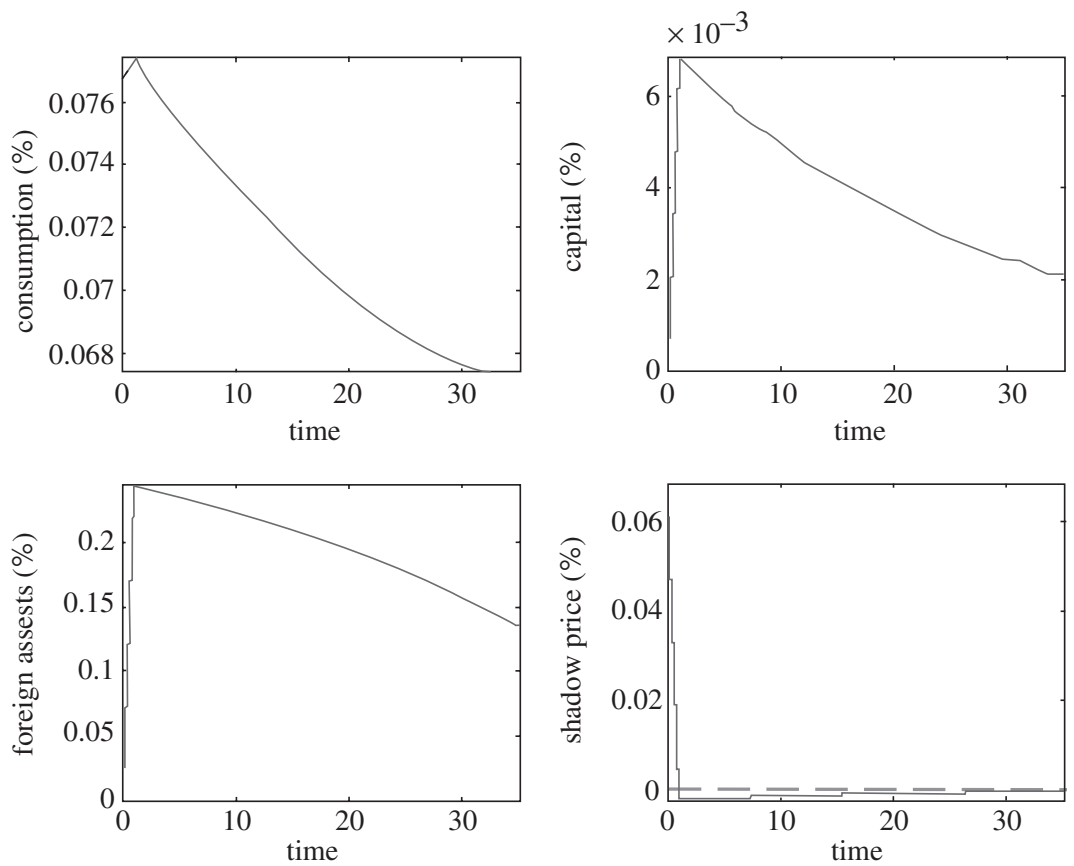

Fig. 1. The effects on the economy from a temporary appreciation in terms of trade

consumption. Hence, in our example, foreign assets decrease in the short run and then increase gradually to converge to the new steady state when the shock is permanent. Because capital goods are imported from foreign countries, an appreciation in terms of trade means that capital goods become cheaper. Hence, in both cases, capital will increase when the terms of trade appreciate. Furthermore, when the shock is permanent, a portfolio substitution effect is discernible between capital and foreign assets in the medium term.

We first examine how susceptible the steady state is to the arrival rate of death. Notice that from Eqs. (4) and (6), we can calculate the steady-state capital stocks in the exportable sector $\left(K_{X}^{*}\right)$ and in the importable sector $\left(K_{M}^{*}\right)$. We find that the steady-state values of $K_{X}^{*}, K_{M}^{*}$ and $K^{*}$ are independent of the arrival rate of death. However, the arrival rate of death will affect households' decisions on consumptions and holdings of foreign assets. If $\beta$ increases, it means that the effective rate of return on non-human wealth will increase and this will increase household holdings of foreign assets. But on the other hand, when $\beta$ increases, consumers will reduce their holdings of 

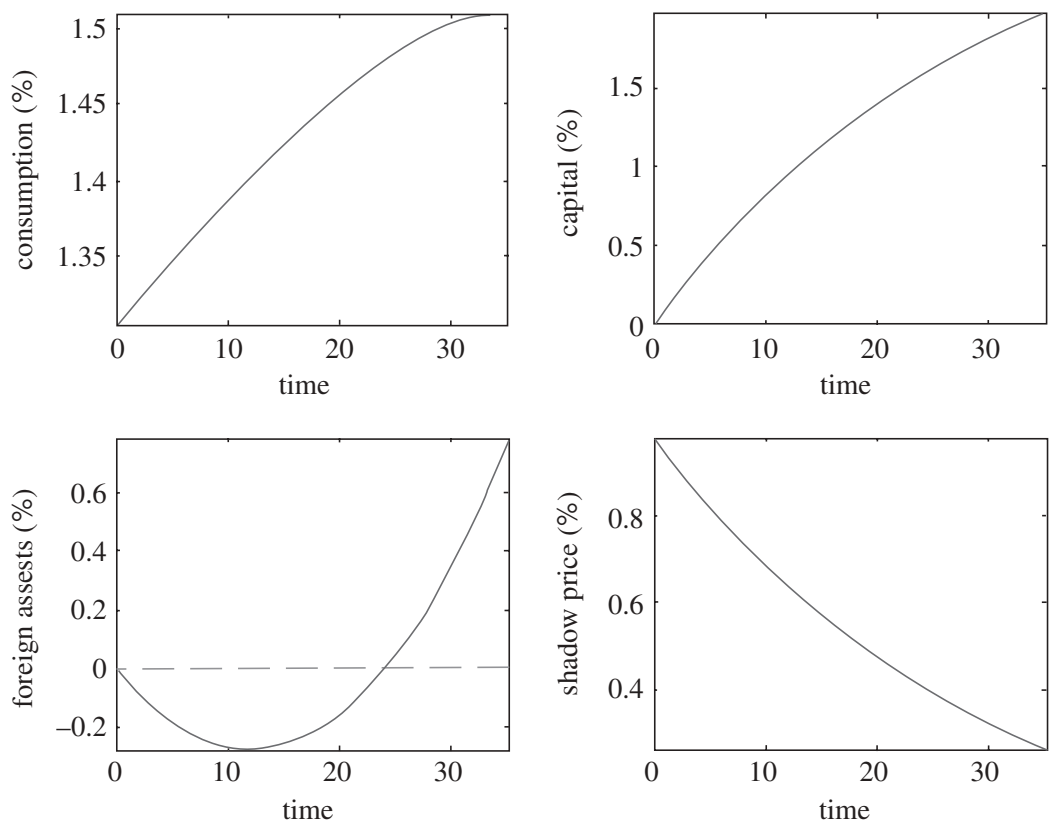

Fig. 2. The effects on the economy from a permanent appreciation in terms of trade

foreign assets and consume more today because the expected lifetime decreases. Hence, the impact of $\beta$ on $F^{*}$ is uncertain. The arrival rate of death affects $C^{*}$ in two ways. An increase in $\beta$ will increase $C^{*}$ directly by decreasing the expectation of the length of lifetime. But it will affect $C^{*}$ indirectly by changing the households' holdings of foreign assets. Therefore, the impact of $\beta$ on $C^{*}$ is also uncertain. Table 1 presents the influences of $\beta(\beta=0,0.015,0.03,0.0332,0.06)$ on $C^{*}$ and $F^{*}$. It shows that the model is very sensitive to $\beta$. Especially, it indicates that a model with infinite lifetime $(\beta=0)$ does not provide a reasonable steady-state equilibrium for a small open economy such as Taiwan because it implies that $C^{*}$ is zero. The reason why there is zero consumption in the steady state when $\beta=0$ is that the global real interest rate is lower than the time preference rate. Hence, consumption decreases over time and approaches zero. ${ }^{15}$

15 The foreign interest rate can be justified to be lower by arguing that the time preference rate abroad is lower. Similar results that consumption goes to zero with international capital flows when agents abroad are more patient than agents at home can be found in Walde (1994). We thank a referee for mentioning this. 
Table 1. Impacts of $\beta$ on $C^{\star}$ and $F^{\star}$

\begin{tabular}{llllll}
\hline$\beta$ & 0 & $1.5 \%$ & $3.0 \%$ & $3.32 \%$ & $6.0 \%$ \\
\hline$C^{\star}$ & 0.0 & -1.3 & 1.6 & 1.4 & 0.9 \\
$F^{\star}$ & -21.0 & 47.1 & 12.3 & 6.9 & -3.5 \\
\hline
\end{tabular}

However, a model with an uncertain lifetime might be able to provide a positive steady-state consumption. Furthermore, the model with $\beta=3.32 \%$ predicts that $C^{*}=1.4$ and $F^{*}=6.9$ which is suitable to describe a small open economy like Taiwan where the holdings of foreign assets are positive. ${ }^{16}$

We then conduct a sensitivity analysis to determine how dependent the speed of convergence is upon the parameters. Note that $\lambda_{1}$ and $\lambda_{2}$ are the negative eigenvalues, respectively corresponding to Eqs. (28) and (29), and note that, according to Eq. (28), $\lambda_{1}$ depends upon the assigned value of $b$. As Table 2 shows, with a rise in the value of $b$, there is a reduction in the absolute value of $\lambda_{1}$; hence, when investment becomes more costly, there is deceleration in the speed of convergence for $K_{t}, \eta_{t}, C_{t}$ and $F_{t}$.

We find from the simulation results that the Harberger-Laursen-Metzler effect is present for temporary and permanent shocks in terms of trade, although these effects are quite weak. ${ }^{17}$ This is similar to the finding by Mendoza (1995) of a weak positive correlation between net exports and terms of trade in an open-economy real business cycle model. It is also interesting to note that, as suggested by Barro and Sala-i-Martin (2004),

Table 2. The relationship between $b$ and $\lambda_{1}$

\begin{tabular}{llllllll}
\hline$b$ & 0.1 & 0.5 & 1.0 & 5.0 & 10.0 & 20.0 & 50.0 \\
\hline$\lambda_{1}$ & -0.498 & -0.212 & -0.145 & -0.056 & -0.035 & -0.022 & -0.011 \\
\hline
\end{tabular}

16 We thank a referee for suggesting us to examine the impacts of $\beta$ on the steady state.

17 We also develop a model where capital is used as an input in the nontradable sector. The simulation results demonstrate that the Harberger-LaursenMetzler effect can be obtained in an economy as long as non-tradable goods are more capital intensive than exportable goods. 
the speed of convergence can be reduced by the presence of adjustment costs in capital formation and imperfect capital mobility.

\section{Conclusions}

In this paper, we study the effects of changes in terms of trade on private spending, capital accumulation and the current account of a small open economy with capital accumulation, utilizing the Blanchard-type uncertain lifetime overlapping generations framework.

It has been clearly demonstrated by several studies (Persson and Svensson, 1985; Brock, 1988, 1996; Matsuyama, 1987, 1988; Buiter, 1989; Sen and Turnovsky, 1989a, 1989b), that that both investment behavior and savings behavior are crucial to the understanding of different exogenous shocks on the current account; thus, we extend the simple model by introducing production and capital accumulation functions into the model.

Assuming that capital goods are imported from foreign countries, the simulation results show that the Harberger-Laursen-Metzler effect will always be present for both temporary and permanent terms of trade shocks. However, foreign assets react differently in the short run when faced with shocks of varying intensity; indeed, in the case of permanent shocks, there is a larger change in consumption and a transitional portfolio substitution effect is discernible between capital and foreign assets. Our numerical exercise shows that the speed of convergence of capital and consumption is quite low. We also find that a finite-horizon model is more suitable to characterize a small open economy such as Taiwan than an infinite-horizon model.

As a concluding note, the nature of capital accumulation is relevant to the dynamics. Brock and Turnovsky (1994) and Brock (1996) showed that if investment is in the form of non-traded goods, then even in the absence of any adjustment costs associated with investment, nondegenerate dynamics are obtained. Moreover, non-recursive dynamics are dependent upon the relative capital intensities of the traded goods and non-traded goods sectors only when the capital is in the form of nontraded goods. In a planned future paper, we aim to try out alternative specifications for investment expenditure in the form of non-traded goods to study the existence of Harberger-Laursen-Metzler effects. 


\section{Appendix 1}

\section{Households' Optimization Problem}

Solving the household's optimization problem from Eqs. (14), (15), (16), (17), (19) and (20), we have:

$$
\begin{gathered}
c(s, t)=\theta(\rho+\beta)\left[a(s, t)+h^{f}(s, t)\right], \\
L(s, t)=\frac{1-\theta}{\theta} \frac{c(s, t)}{W_{N}(s, t)}, \\
P_{X}(t) c_{X}(s, t)=\mu_{X} c(s, t), \\
c_{M}(s, t)=\mu_{M} c(s, t) \\
P_{N}(t) c_{N}(s, t)=\mu_{N} c(s, t) .
\end{gathered}
$$

By aggregation, we obtain:

$$
\begin{gathered}
C(t)=\beta \int_{-\infty}^{t} c(s, t) e^{\beta(s-t)} d s=\theta(\rho+\beta)\left[A(t)+H^{f}(t)\right], \\
L(t)=\beta \int_{-\infty}^{t} L(s, t) e^{\beta(s-t)} d s=\frac{1-\theta}{\theta} \frac{C(t)}{W_{N}(t)},
\end{gathered}
$$

where

$$
\begin{gathered}
A(t)=\beta \int_{-\infty}^{t} a(s, t) e^{\beta(s-t)} d s, \\
H^{f}(t)=\beta \int_{-\infty}^{t} h^{f}(s, t) e^{\beta(s-t)} d s .
\end{gathered}
$$




\section{Appendix 2}

Analysis of Dynamic Systems

In this Appendix, we study the dynamic system presented in the penultimate section of the paper. We should begin by noting that the dynamic system (27) is block recursive. There are two predetermined variables, $K$ and $F$, and two jumping variables, $\eta$ and $C$. Let $\lambda_{1}$ and $\lambda_{2}$ represent negative eigenvalues which respectively correspond to Eqs. (28) and (29). The number of predetermined variables is equal to the number of negative eigenvalues. The unique stable path to the steady state is thus:

$$
\begin{gathered}
K_{t}-K^{*}=V_{11} e^{\lambda_{1} t}, \\
\eta_{t}-1=V_{21} e^{\lambda_{1} t}, \\
C_{t}-C^{*}=V_{31} e^{\lambda_{1} t}+V_{32} e^{\lambda_{2} t}, \\
F_{t}-F^{*}=V_{41} e^{\lambda_{1} t}+V_{42} e^{\lambda_{2} t} .
\end{gathered}
$$

Solving for $V_{11}, V_{21}, V_{31}, V_{32}, V_{41}$ and $V_{42}$, we obtain:

$$
\begin{gathered}
V_{11}=K_{0}-K^{*}, \\
V_{21}=\pi\left(\lambda_{1}-r\right)^{-1}\left(K_{0}-K^{*}\right), \\
V_{31}=\theta \beta(\rho+\beta) \pi K^{*} \Delta^{-1}\left(K_{0}-K^{*}\right), \\
V_{32}=\theta\left(\mu_{X}+\mu_{M}\right)^{-1}\left(r-\lambda_{2}\right) V_{42} \\
V_{41}=-V_{11}-\left(\mu_{X}+\mu_{M}\right) \theta \beta(\rho+\beta) \pi K^{*} \Delta^{-1}\left(\lambda_{1}-r\right)^{-1}\left(K_{0}-K^{*}\right), \\
V_{42}=F_{0}-F^{*}-V_{41},
\end{gathered}
$$

where 


$$
\pi=-M_{K K} K_{M}^{\prime}\left(K^{*}\right), \quad \Delta=\left|\begin{array}{cc}
r-\rho-\lambda_{2} & -\theta \beta(\rho+\beta) \\
\mu_{X}+\mu_{M} & \lambda_{2}-r
\end{array}\right| .
$$

Hence, we can rewrite Eqs. (A2.1), (A2.2), (A2.3) and (A2.4) as

$$
\begin{gathered}
K_{t}-K^{*}=\left(K_{0}-K^{*}\right) e^{\lambda_{1} t} \\
\eta_{t}-1=\pi\left(\lambda_{1}-r\right)^{-1}\left(K_{0}-K^{*}\right) e^{\lambda_{1} t} \\
C_{t}-C^{*}=\theta \beta(\rho+\beta) \pi K^{*} \Delta^{-1}\left(\frac{r-\lambda_{2}}{\lambda_{1}-r} e^{\lambda_{2} t}+e^{\lambda_{1} t}\right) \\
+\left(A_{0}-A^{*}\right)\left(\mu_{X}+\mu_{M}\right)^{-1}\left(r-\lambda_{2}\right) e^{\lambda_{2} t}, \\
F_{t}-F^{*}=\left(K_{0}-K^{*}\right)\left[\left(\mu_{X}+\mu_{M}\right) \theta \beta(\rho+\beta) \pi K^{*} \Delta^{-1}\left(\lambda_{1}-r\right)^{-1}\right. \\
\left.\times\left(e^{\lambda_{2} t}-e^{\lambda_{1} t}\right)-e^{\lambda_{1} t}\right]+\left(A_{0}-A^{*}\right) e^{\lambda_{2} t} .
\end{gathered}
$$

* Note that the model reduces to Matsuyama's (1987) model when $\mu_{X}+\mu_{M}=1$ and $\theta=1$.

\section{Acknowledgements}

The authors gratefully acknowledge financial supports from the Program for Globalization Studies, Institute for Advanced Studies in Humanities and Social Sciences and the Center for Public Economic Studies, College of Social Science, National Taiwan University. We are grateful to Henry Wan and several seminar participants at the Institute of Economics, Academia Sinica in Taiwan for their comments. We would especially like to thank the editor Giacomo Corneo and two anonymous referees for their helpful comments and suggestions. All errors are our responsibility

\section{References}

Barro, R. J., and Sala-i-Martin, X. (2004): Economic Growth. New York: McGraw-Hill.

Blanchard, O. J. (1985): “Debt, Deficit and Finite Horizons.” Journal of Political Economy 93: 223-47.

Brock, P. L. (1988): "Investment, the Current Account and the Relative Price of Non-traded Goods in a Small Open Economy." Journal of International Economics 24: 235-53. 
Brock, P. L. (1996): "International Transfers, the Relative Price of Non-traded Goods and the Current Account." Canadian Journal of Economics 29: 306-25.

Brock, P. L., and Turnovsky, S. J. (1994): "The Dependent Economy Model with Both Traded and Non-traded Capital Goods." Review of International Economics 3: 306-25.

Buiter, W. H. (1989): Budgetary Policy, International and Intertemporal Trade in the Global Economy. Amsterdam: Elsevier.

Cashin, P., and McDermott, C. J. (2002): "Terms of Trade Shocks and the Current Account: Evidence from Five Industrial Countries." Open Economies Review 13: 219-35.

CEPD (2000): Taiwan Statistical Data Book. Taipei: Council for Economic Planning and Development.

Chen, H.-J., Hsu, C.-M., and Lian, K.-S. (2005): "Terms of Trade Shocks and Current Account in a Finite-Horizon Economy." mimeo, National Taiwan University.

Codsi, G., Person, K. R., and Wilcoxen, P. J., (1992): “General Purpose Software for Intertemporal Economic Models." Computer Science in Economics and Management 5: 57-79.

DGBAS (2000): Monthly Bulletin of Earnings and Productivity Statistics, Taiwan Area. Taipei: Directorate-General of Budget, Accounting and Statistics.

Diamond, P. A. (1965): "National Debt in a Neoclassical Growth Model." American Economic Review 55: 1126-50.

Dixon, P. B., Parmenter, B. R., Powell, A. A., and Wilcoxen, P. J. (1992): Notes and Problems in Applied General Equilibrium Economics. Amsterdam: NorthHolland.

Engel, C., and Kletzer, K. (1990): "Tariffs and Saving in a Model with New Generations." Journal of International Economics 28: 71-91.

Frenkel, J. A., and Razin, A. (1987): Fiscal Policies and the World Economy. Cambridge, MA: MIT Press.

Hayashi, F. (1982): “Tobin's Marginal q and Average q: A Neoclassical Interpretation." Econometrica 50: 213-24.

Hansen, G. D., and Imrohoroglu, A. (1992): "The Role of Unemployment Insurance in an Economy with Liquidity Constraints and Moral Hazard." Journal of Political Economy 100: 118-142.

Harberger, A. C. (1950): "Currency Depreciation, Income and the Balance of Trade." Journal of Political Economy 58: 47-60.

Harrison, W. J., and Pearson, K. R. (1996): "Computing Solutions for Large General Equilibrium Models Using GEMPACK.” Computational Economics 9: 83-127.

Laursen, S., and Metzler, L. A. (1950): "Flexible Exchange Rates and the Theory of Employment." Review of Economics and Statistics 32: 281-99.

Klundert, T. V., and Ploeg, F. (1989): "Fiscal Policy and Finite Lives in Interdependent Economies with Real and Nominal Wage Rigidity." Oxford Economic Papers 41: 459-89.

Kose, M. A. (2002): "Explaining Business Cycles in Small Open Economies: How Much Do World Prices Matter?" Journal of International Economics 56: 299-327. 
Mahbub Morshed, A. K. M., and Turnovsky, S. J. (2004): "Sectoral Adjustment Costs and Real Exchange Rate Dynamics in a Two-sector Dependent Economy". Journal of International Economics 63: 147-177.

Matsuyama, K. (1987): "Current Account Dynamics in a Finite Horizon Model." Journal of International Economics 23: 299-313.

Matsuyama, K. (1988): "Terms of Trade, Factor Intensities and the Current Account in a Life Cycle Model." Review of Economic Studies 55: 247-62.

Mendoza, E. G. (1995): "Terms of Trade, the Real Exchange Rate and Economic Fluctuations." International Economic Review 36: 101-37.

Obstfeld, M. (1982a): "Aggregate Spending and Terms of Trade: Is There a Laursen-Metzler Effect?” Quarterly Journal of Economics 97: 251-70.

Obstfeld, M. (1982b): "Transitory Terms of Trade Shocks and the Current Account: the Case of Constant Time Preference." NBER Working Paper Series No. 834.

Obstfeld, M. (1983): "Intertemporal Price Speculation and the Optimal Current Account Deficit." Journal of International Money and Finance 2: 135-45.

Ostry, J. D. (1988): "Balance of Trade, Terms of Trade and the Real Exchange Rate: An Intertemporal Optimizing Framework." IMF Staff Papers 35: 541-73.

Ostry, J. D., and Reinhart, C. M. (1992): "Private Saving and Terms of Trade Shocks: Evidence from Developing Countries." IMF Staff Papers 39: 495-517.

Otto, G. (2003): "Terms of Trade Shocks and the Balance of Trade: There Is a Harberger-Laursen-Metzler Effect." Journal of International Money and Finance 22: 155-84.

Persson, T., and Svensson, L. (1985): "Current Account Dynamics and the Terms of Trade: Harberger-Laursen-Metzler Two Generations Later." Journal of Political Economy 93: 43-65.

Sen, P., and Turnovsky, S. J. (1989a): "Deterioration of Terms of Trade and Capital Accumulation: A Re-Examination of the Laursen-Metzler Effect." Journal of International Economics 26: 227-50.

Sen, P., and Turnovsky, S. J. (1989b): "Tariffs, Capital Accumulation and the Current Account in a Small Open Economy." International Economic Review 30: 811-31.

Svenson, L. E. O., and Razin, A. (1983): “The Terms of Trade and the Current Account: the Harberger-Laursen-Metzler Effect." Journal of Political Economy 91: 97-125.

Walde, K. (1994): "Unequal Factor Prices and Incomplete Specialization in a Heckscher-Ohlin Model of Endogenous Growth." Journal of Economics 59: 311-323.

Walde, K. (1999): "Proof of Global Stability, Transitional Dynamics, and International Capital Flows in a Two-country Model of Innovation and Growth." Journal of Economics 64: 53-84.

Yaari, M. E. (1965): "Uncertain Lifetime, Life Insurance and the Theory of the Consumer." Review of Economic Studies 32: 137-50.

Address of authors: - Hung-Ju Chen and Chen-Min Hsu, Department of Economics, National Taiwan University, 21 Hsu-Chow Road, Taipei 100, Taiwan (e-mail: hjc@ntu.edu.tw) 